\title{
ARQUITETURA CURATIVA DO SANATÓRIO SANTA TEREZINHA, EM SALVADOR, BA
}

\author{
CARVALHO, Antonio Pedro Alves de \\ Universidade Federal da Bahia, e-mail: pedro@ufba.br \\ GUEDES, Felix de Jesus \\ Universidade Federal da Bahia, e-mail: felixjguedes@gmail.com \\ SOUZA, Cleiton Marques de Jesus \\ Universidade Federal da Bahia, e-mail: cleitonmjs@gmail.com
}

\begin{abstract}
RESUMO
O presente artigo é resultado de uma das etapas da pesquisa acerca do meio ambiente de edificações de saúde, em andamento, financiada pelo CNPQ, tendo a participação de bolsistas de iniciação científica. Seu objetivo foi demonstrar, através da análise das condições ambientais no Hospital Sanatório Santa Terezinha, inaugurado em 1941, em Salvador, BA, o planejamento efetuado por arquitetos modernistas para o uso da helioterapia e da ventilação cruzada como auxílio na cura da tuberculose, demonstrando a intenção de que a arquitetura participasse do processo curativo. A metodologia utilizada foi a pesquisa bibliográfica sobre as características desse tipo de edificação, a visita e cadastro do edifício e a análise de suas condicionantes climáticas utilizando programas computacionais. Como resultado, pôde-se observar a intencionalidade dos arquitetos em proporcionar condições de incidência controlada de sol e de ventos, que permitissem o conforto e o auxílio ao restabelecimento dos pacientes. Espera-se que o planejamento climático constatado contribua como exemplo do uso da arquitetura como fator de apoio aos procedimentos de restabelecimento da saúde.
\end{abstract}

Palavras-chave: Arquitetura Hospitalar, Sanatórios, Modernismo, Conforto Climático.

\begin{abstract}
This article is the result of research on the health buildings environment, underway, financed by $C N P Q$, with scientific initiation fellows participation. Its objective was to demonstrate, through the analysis of the environmental conditions at the Sanatorio Santa Terezinha Hospital, inaugurated in 1941, in Salvador, Bahia, the planning done by modernists architects with the use of heliotherapy and cross ventilation to aid the tuberculosis cure, demonstrating the intention of architecture to participate in the healing process. The methodology used was the bibliographic research on the characteristics of this type of building, the visit, registration and the analysis of its climatic conditions using computer programs. As a result, it was possible to observe the intentionality of the architects in providing conditions of sun and winds controlled incidence, that allowed the comfort and the aid patients cure. It is hoped that climate planning will contribute as an example of architecture as a support factor for health restoration procedures.
\end{abstract}

Keywords: Hospital Architecture, Sanatoriums, Modernism, Climatic Comfort.

\section{INTRODUÇÃO}

No final do século XIX e início do século XX, experimentou-se mundialmente uma epidemia de tuberculose. Apesar de sua multicausalidade, pode-se apontar $o$ veloz processo de urbanização e as condições precárias de

CARVALHO, A. P. A.; GUEDES, F. J.; SOUZA, C. M. J. Arquitetura curativa do Sanatório Santa Terezinha, em Salvador, BA. In: SIMPÓSIO BRASILEIRO DE QUALIDADE DO PROJETO NO AMBIENTE CONSTRUÍDO, 6., 2019, Uberlândia. Anais... Uberlândia: PPGAU/FAUeD/UFU, 2019. p. 1039-1049. DOI https://doi.org/10.14393/sbqp19095. 
habitação como fatores determinantes da rápida proliferação da doença. Segundo Quecedo (2012. p. 38): "[...] a tuberculose, mais tarde chamada peste branca, arrasa o continente europeu e chega, no princípio do século XX, a ser a primeira causa de mortalidade em toda Europa".

Como o seu contágio pode se processar por via aérea, a alta densidade populacional e deficientes condições de aeração são características físicas habitacionais negativas. Salvador, capital da Bahia, foi uma das cidades brasileiras onde a epidemia se abateu com maior intensidade. Em 1935, morriam 1600 pessoas por ano de tuberculose nesta capital, que possuía o mais elevado índice de letalidade do Brasil - 400/100.000 habitantes (MACHADO, 2007).

Como reação das autoridades sanitárias, considerando a falta de medicamentos eficientes de combate à doença, a primeira providência foi o isolamento dos casos, como era procedimento comum nas epidemias da época. Para tanto, estabeleceram-se edificações isoladas, através do aluguel de casas em sítios e fazendas, ou a construção de hospitais (SANTOS, 2005).

Essa época era uma fase de transição entre o paradigma de causalidade das doenças infecciosas pelos chamados miasmas e as novas hipóteses de atuação dos micro-organismos, precedendo a descoberta dos antibióticos. Nesse período, a busca de soluções de melhor adequação ambiental era comum, com a defesa dos hospitais de tipologia pavilhonar, com limitação de doentes por enfermaria e favorecimento da ventilação e entrada do sol.

O higienismo, no período, apontava as deficiências de alimentação, excesso de trabalho, habitação insalubre, pobreza e alcoolismo, que muito se deviam à exploração do trabalhador no início da revolução industrial, como causas da proliferação da tuberculose. Apesar da descoberta do bacilo de Koch como o causador da doença, em 1882, e a pesquisa com vacinas, apenas em 1944 encontrou-se um antibiótico eficiente para a cura da doença, tornandose desnecessária a internação (ROCHA, 2015).

No início do século XX, para o tratamento da tuberculose, foram feitas, nos doentes, com sucesso, experiências de exposição solar e exercícios respiratórios em ambientes livres de polvição, tornando as condições ambientais que favorecessem estes procedimentos desejáveis nas edificações de saúde projetadas para este fim.

\section{O SURGIMENTO DOS SANATÓRIOS E O SANATÓRIO SANTA TEREZINHA}

\subsection{Os Sanatórios}

A criação de sanatórios para o tratamento da tuberculose foi uma tendência no tratamento de saúde que atingiu todo o mundo ocidental. De acordo com Rocha (2015), o primeiro hospital com a finalidade específica de tratamento da tuberculose foi o Royal Sea Bathing Infirmary for Scrofula, fundado em 1791, na Inglaterra. Nesta instituição era defendida a terapia de exercícios respiratórios junto ao mar.

Os sanatórios eram instituições de longa permanência com forte apelo hoteleiro, que necessitavam de amplas áreas externas para a deambulação, exercícios físicos, ar puro, sol e lazer. A internação era provocada essencialmente pela necessidade de isolamento do doente e não por estar 
incapacitado de locomover-se. Essas características indicavam a localização em áreas elevadas, vegetação circundante e sem polvição, o que implicava em estar longe dos centros urbanos. A concomitante criação de dispensários, para o atendimento ambulatorial de pacientes menos graves, e a facilitação de visitas de parentes, ampliava a importância de boa acessibilidade.

A necessidade de colocar os aposentos dos doentes na melhor disposição relativamente ao sol e ventilação induziu ao uso de formas alongadas e extensas varandas. Este fator e a necessidade de separação das alas masculinas e femininas, conduziram a um partido arquitetônico que impunha a centralização dos espaços de apoio de uso comum, resultando em uma solução arquitetônica em planta simétrica em forma de "T".

A forma adotada pelo Sanatório Santa Terezinha foi inspirada em modelos europeus, como o Hospital de Berna, Suiça (1930) (Figura 01), o Pavilhão de Tuberculose do Hospital de San Sebastian, Espanha (1933) e o Centro Sanatorial de Forli, na Itália (1934) (QUECEDO, 2012, p. 138).
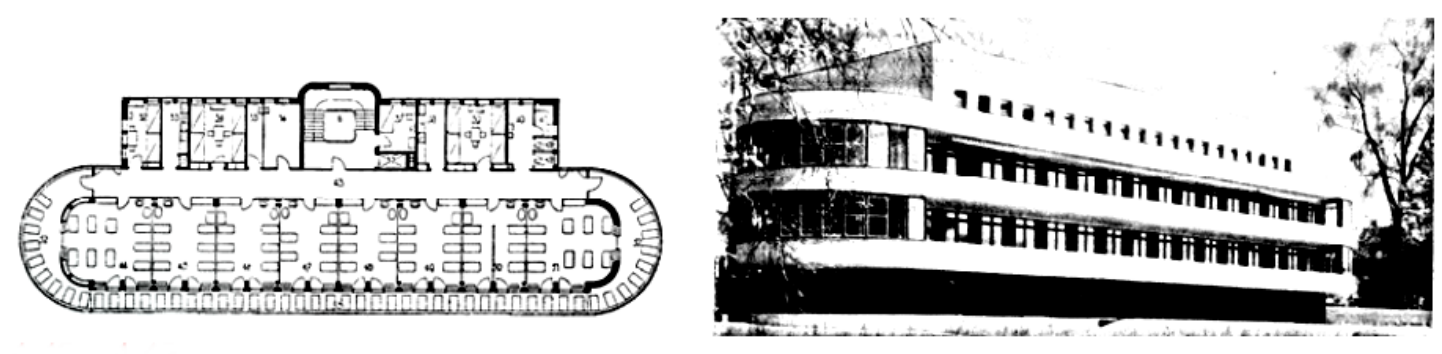

Figura 1 - Hospital de Berna, Suiça, 1930, que utilizava a helioterapia e possuía um partido arquitetônico semelhante ao Sanatório Santa Terezinha -

Fonte: QUECEDO (2012, p. 138)

O formato com extremidades arredondadas, propiciava um melhor aproveitamento da varanda para o banho de sol, que, dessa forma, se adaptaria mais eficientemente às diversas estações do ano.

\subsection{O Sanatório Santa Terezinha}

O Hospital Sanatório Santa Terezinha foi construído entre 1937 e 1942, tendo como autores do projeto arquitetônico o arquiteto carioca Jorge Moreira, que possuía experiência na área hospitalar, e Diógenes Rebouças, arquiteto baiano, que cuidou dos detalhes de aprovação local e acompanhamento da construção (ANDRADE JÚNIOR, 2011). Seu estilo é marcadamente modernista, com traços geométricos, sendo um dos ícones da arquitetura baiana, estando a edificação em processo de tombamento. De acordo com Bierrenbach (2017), "[...] seu volume é demarcado por linhas horizontais e extremidades curvas [...]" (Figura 2). Está localizado na cidade de Salvador, no bairro do Pau Miúdo.

A implantação do hospital se deu em área elevada da cidade, que, inicialmente, era isolada e, hoje, possui edificações com o gabarito baixo, não apresentando barreiras que atrapalhem a incidência dos raios solares ou a boa captação dos ventos.

O edifício principal do sanatório possui cinco pavimentos, sendo o térreo reservado para serviços administrativos e ambulatoriais, o primeiro e segundo pavimentos para enfermarias de quatro ou seis leitos e os terceiro e quarto 
pavimentos, que têm largura menor, para quartos individuais. Suas enfermarias e quartos são colocados de forma contígua, com acesso em corredor monocarga - isto é, com compartimentos apenas de um lado. Como resultado desse partido, sua volumetria é marcadamente longitudinal, no sentido noroeste e sudeste, apresentando comprimento máximo de $110 \mathrm{~m}$ e largura de 10m (SOUZA; BARRETO, 2011) (ver Figuras 3 e 4).

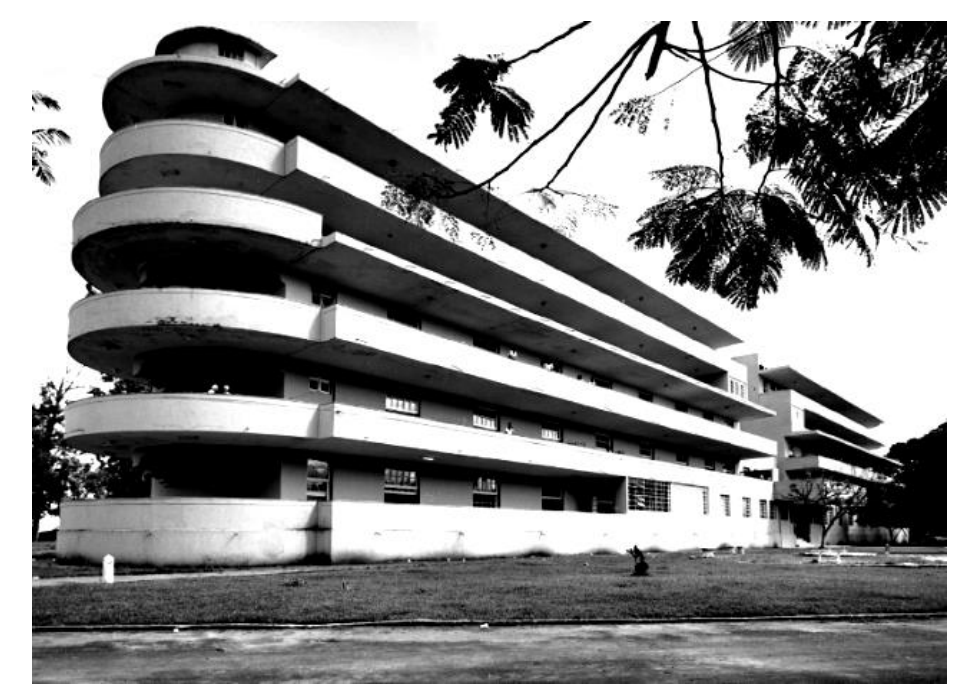

Figura 2 - Vista do Hospital Sanatório Santa Terezinha na época da inauguração Fonte: SOUZA; BARRETO (2011)

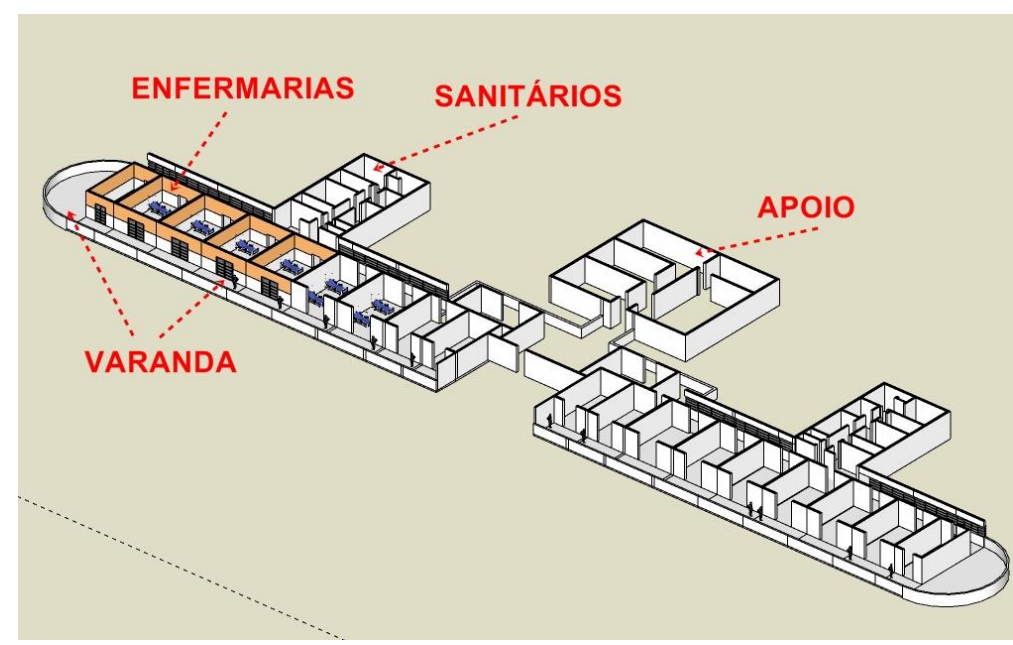

Figura 3 - Esquema de planta do segundo piso do edifício principal do Sanatório Santa Terezinha -

Fonte: Elaborado pelos autores

Essa disposição favorece o acesso a uma grande varanda, que proporciona a incidência solar em períodos controlados. Ligadas ao corpo principal do edifício, existem três blocos, sendo duas prumadas de sanitários e uma de apoio de enfermagem.

As varandas permitem a incidência solar ao longo das manhãs e o bloqueio nos horários de maior temperatura. O hospital foi projetado para a utilização do princípio da helioterapia, tratamento de exposição do paciente aos raios solares, defendido na época para os acometidos de tuberculose. Para atender a essa demanda, o edifício foi implantado em posição condizente com as direções de sol e ventos. 


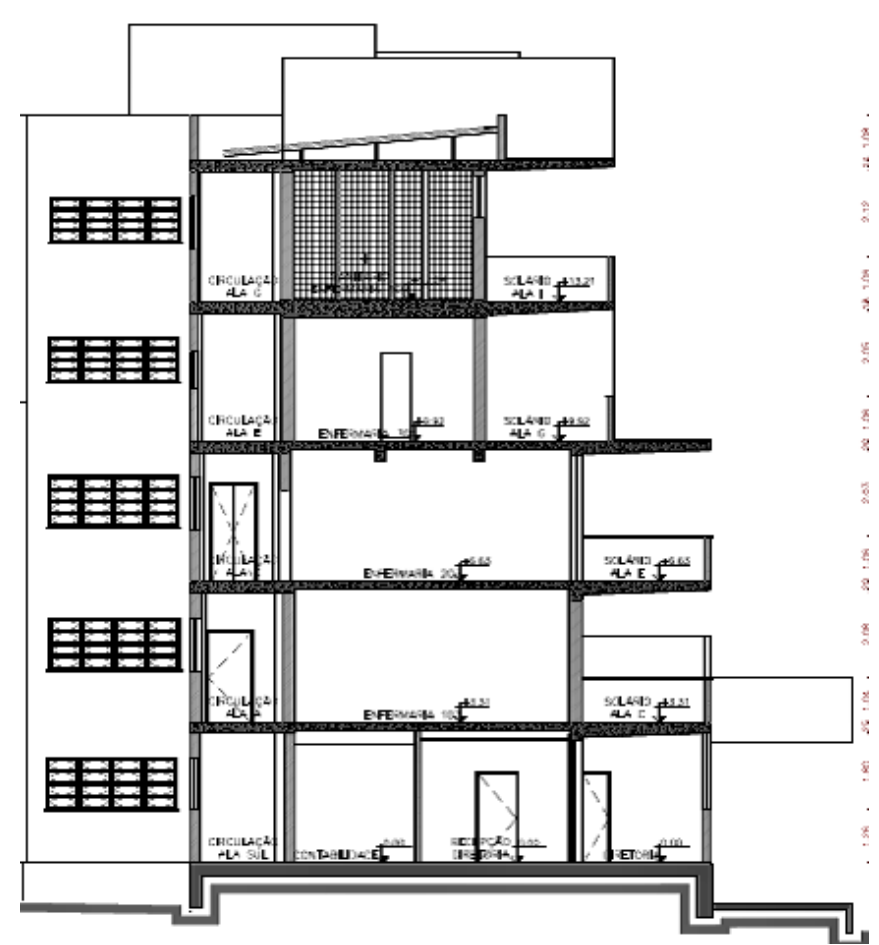

Figura 4 - Corte Esquemático do edifício principal do Sanatório Santa Terezinha Fonte: Figura cedida por Matos e Otembra (2018)

Ao longo dos anos de operação, o hospital passou por várias atualizações, além de construções de anexos, sendo responsável pelo tratamento de diversas doenças respiratórias. A tuberculose deixou de apresentar grandes riscos à população, pois o tratamento ambulatorial se tornou mais eficaz, diminuindo o número de mortes, perdendo a necessidade de uma instituição destinada somente ao cudado desta doença.

\subsection{Análise das condições de incidência solar}

A norma técnica de Desempenho Térmico de Edificações, NBR 15220 (ABNT, 2005) estabelece o Zoneamento Bioclimático Brasileiro. Nesta norma, são feitas recomendações de diretrizes construtivas e detalhamento de estratégias de condicionamento térmico passivo que aperfeiçoam o desempenho das edificações através de sua melhor adequação climática.

O setor número oito do Zoneamento Bioclimático Brasileiro, em que se encontra a cidade de Salvador, indica que essa região passa $48 \%$ do ano em desconforto térmico por conta do calor e, por isso, possui as recomendações técnico construtivas de adoção de sombreamento e grandes aberturas, para permitir a entrada de ventos.

Ao redor do hospital existem massas de vegetação que influenciam no condicionamento do microclima. A vegetação, por conta do fenômeno da evapotranspiração, altera o nível da umidade local, podendo aumentá-lo. As áreas vegetais, além disso, refletem menor quantidade de radiação, contribuindo para a diminuição do calor. A massa de vegetação circundante ao hospital, portanto, atua proporcionando a regulação da temperatura ambiente.

A fachada principal da edificação está orientada para Nordeste. Nessa fachada se encontram as varandas, ambientes que permitem a incidência 
solar no período de menor temperatura, como se percebe na análise da Figura 5.

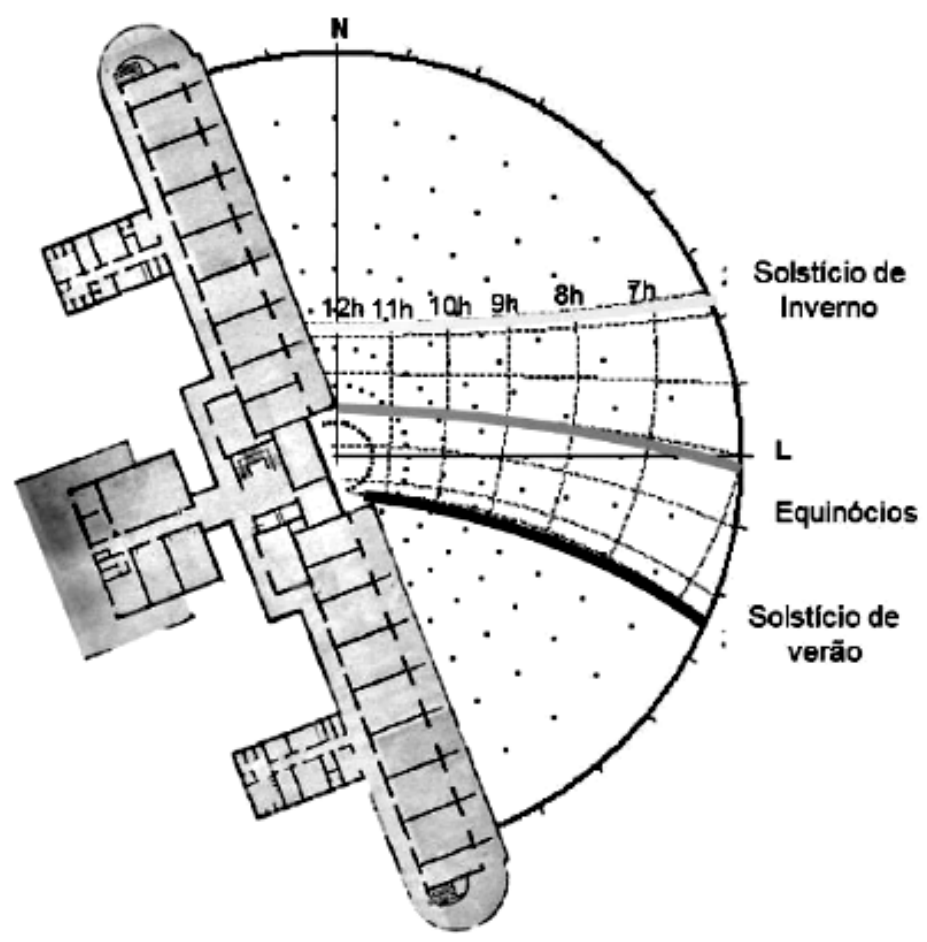

Figura 5 - Orientação e percurso solar na fachada principal do Sanatório Santa Terezinha -

Fonte: Autores, utilizando o programa Analysis SOL-AR (2019)

Solstício de Inverno (21/06)

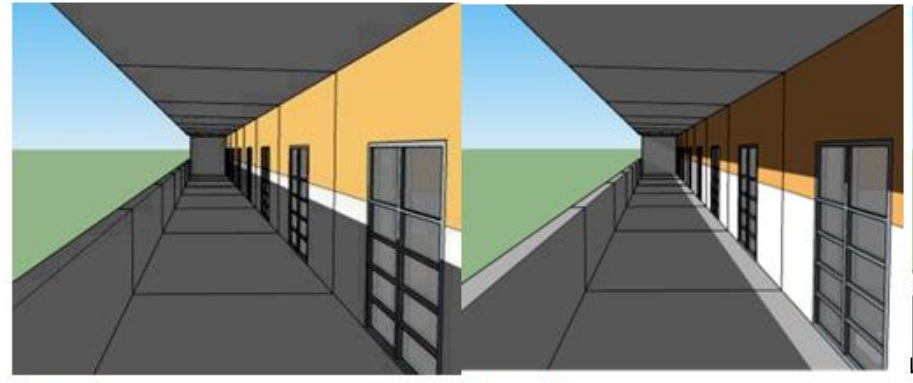

$06: 00 \mathrm{~h}$

$08: 00 \mathrm{~h}$

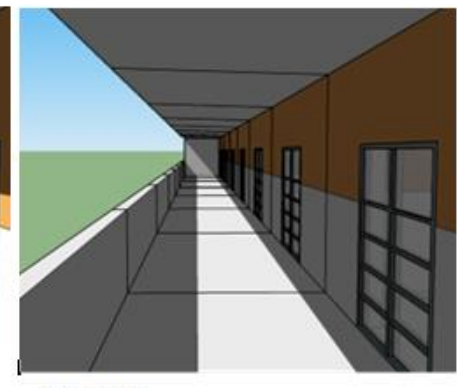

$10: 00 \mathrm{~h}$

Solstício de Verão (21/12)

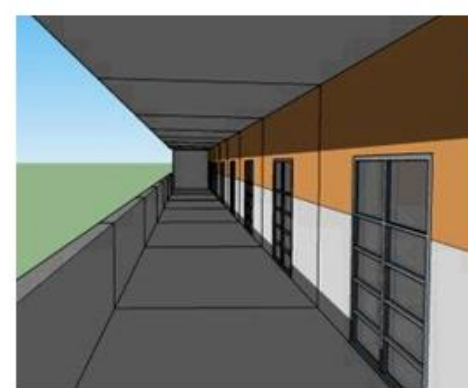

06:00 h

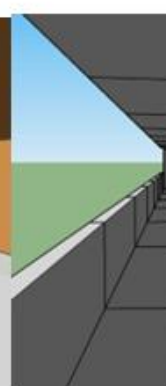

$08: 00 \mathrm{~h}$

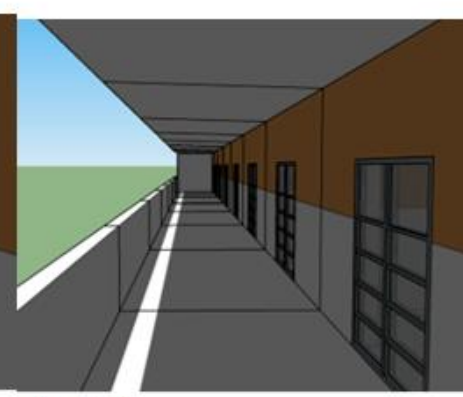

$10: 00 \mathrm{~h}$

Figura 6 - Caminhamento do sol nas varandas do sanatório nos solstícios de inverno e de verão - 
A forma arquitetônica do hospital, juntamente com a disposição dos seus espaços, permite que todos os alojamentos de pacientes tenham ligação direta ao exterior, condição que facilita a exploração da luz e ventilação cruzada para o conforto e uso profilático.

A varanda de cada pavimento é sombreada por conta da laje do pavimento superior. As varandas proporcionam, assim, os banhos de sol ao longo das manhãs e o bloqueio nos horários de maior temperatura.

Observa-se, na Figura 6, estudos do caminhamento solar em horários diversos, na varanda da fachada principal da edificação, efetuado com o software Sketchup (2019), demonstrando a forma de incidência nos solstícios de verão e inverno, demonstrando percurso maior do sol no período de menor calor.

A orientação do edifício, portanto, foi colocada de forma a permitir o uso da helioterapia diariamente, durante todo o ano, proporcionando uma condição ambiental favorável a todos os pacientes internados. A orientação Nordeste da fachada maximiza o período solar nas estações chuvosas, permitindo uma maior probabilidade de incidência e uso terapêutico.

\subsection{Análise das condições de ventilação}

A ventilação é uma estratégia utilizada com o objetivo de se obter o condicionamento térmico de uma edificação através da movimentação do ar. O fluxo de ar retira o excesso de calor acumulado nos ambientes internos, aquecidos pelos usuários e outras fontes, promovendo a troca térmica entre os ambientes. Em climas quentes e úmidos, como em Salvador, torna-se essencial, para o conforto térmico, na maior parte do ano, o aproveitamento da ventilação natural.

Essa renovação de ar permite também a higienização do ambiente, retirando partículas sólidas, odores indesejáveis, reduzindo a concentração de $\mathrm{CO}_{2} \mathrm{e}$ micro-organismos. Os ventos diminuem, além disso, o excesso de vapor d'água no ar interno, regulando a temperatura e diminuindo a probabilidade de contaminação por via aérea.

Pelo estudo da rosa dos ventos para Salvador (Figura 7), observam-se as direções incidentes no hospital, indicando maior fluxo do vento leste no solstício de verão. A fachada Nordeste, para onde abrem as varandas e as enfermarias, é beneficiada por essa ventilação, fato que garante o condicionamento térmico, combatendo o desconforto gerado pela alta umidade da cidade, que varia em torno de $80 \%$.

Chu, Chen e Chen (2011) realizaram um estudo que analisou a influência da taxa de ventilação de edifícios em relação ao ar interno, com modelos apresentando aberturas em somente um e nos dois lados, sob várias direções do vento. Concluíram que a taxa de entrada do ar fresco é superior quando atrelada à existência de um ângulo entre $45^{\circ}$ e $67,5^{\circ}$ em relação à fachada e à direção do vento predominante, devendo a edificação possuir duas aberturas opostas. Essa faixa de ângulos provoca maiores diferenças de pressões externas e internas, aumentando a velocidade de circulação do ar. Nestas condições o fluxo de ar percorre todo o ambiente interno, evitando pontos de estagnação e proporcionando a eficiente passagem do ar fresco.

A orientação da fachada do edifício a $67,5^{\circ}$ do vento leste - predominante nos meses de maior calor - e a disposição dos espaços internos do hospital e 
suas esquadrias, possibilitam a fluidez da circulação do ar, facilitando a ventilação cruzada, estratégia que estimula o fluxo pelos ambientes e entre o ambiente externo e o ambiente interno, induzindo um efeito de troca total do ar interno dos quartos e enfermarias.

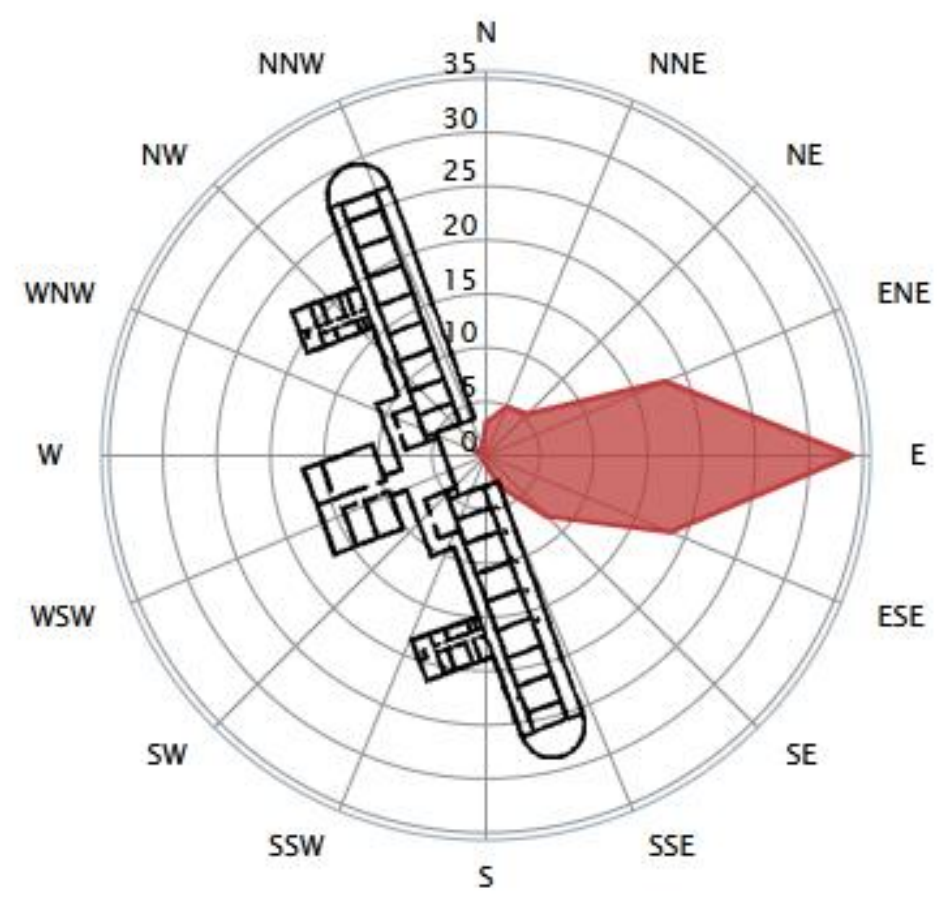

Figura 7 - Rosa dos ventos de Salvador no solstício de verão aplicada ao Sanatório Santa Terezinha -

Fonte: Autores, baseado em Windfinder (2019)

A ventilação natural passiva, como estratégia de projeto, pode ser obtida por conta da incidência dos ventos nas edificações ou do efeito chaminé (MORAIS; LABAKI, 2017). Para avaliar o comportamento da interação da ventilação natural, mais especificamente o impacto da ventilação cruzada, com o conforto térmico experimentado por usuários do hospital, foi realizado um mapeamento qualitativo das linhas de escoamento da ventilação nos ambientes internos do hospital.

A simulação foi realizada pela metodologia da dinâmica de fluidos computacional (CFD-Computer Fluid Dynamics), método no qual a geometria de um modelo existente é analisada como sendo uma rede de nós (ANDERSON, 1995). Com base nos parâmetros de entrada que edificação real experimenta, a rede é utilizada para determinar o funcionamento do modelo. Os resultados do teste CFD são vetores, logo, podem ser analisados quanto a sua orientação (qualitativamente) e velocidade (quantitativamente), fator que possibilita a esse método resultados com uma precisão superior àqueles apresentados por outros mais simplificados.

O software escolhido para a realização dos testes de fluxo do vento leste foi o AutoDesk Flow Design (2019), no qual foi aplicado o modelo tridimensional do hospital, executado no software Sketchup (2019), feito com base no seu 
cadastramento. Ressalta-se, no entanto, que a simulação se vale de três hipóteses simplificadoras:

- A ventilação natural foi considerada apenas como sendo gerada pela diferença de pressão ocasionada pela ação dos ventos na edificação;

- O pavimento de estudo foi considerado isolado para fins de simulação da ventilação interna;

- Não foi avaliada a interação da topografia e edificações vizinhas.

Devido a essas simplificações somente foi possível a representação dos resultados qualitativamente (imagem de caracterização das linhas de fluxo do vento nos ambientes internos).

O período adotado para o mapeamento das linhas de escoamento corresponde aos meses com as médias de temperatura anuais mais quentes do ano (outubro, novembro e dezembro). A direção dominante do vento leste $\left(67,5^{\circ}\right)$, de acordo com observações feitas entre outubro de 2002 a abril de 2019, diariamente das 7 às 19 horas, hora local, na estação meteorológica localizada no aeroporto da cidade de Salvador, informado pela página Windfinder (2019).

Com o resultado obtido (Figura 8) pode-se observar, em planta, o modelo do Hospital Sanatório Santa Terezinha com a distribuição qualitativa das linhas do escoamento do vento em seu interior, que indicam a comprovação da ocorrência do efeito de ventilação cruzada.

A ventilação cruzada ocorre no hospital com a penetração do vento através das varandas, enfermarias e corredor. Na simulação, notam-se pontos de diferentes concentrações de linhas de fluxo de vento, que se dão devido à diferença nas dimensões das esquadrias adotadas no edifício.

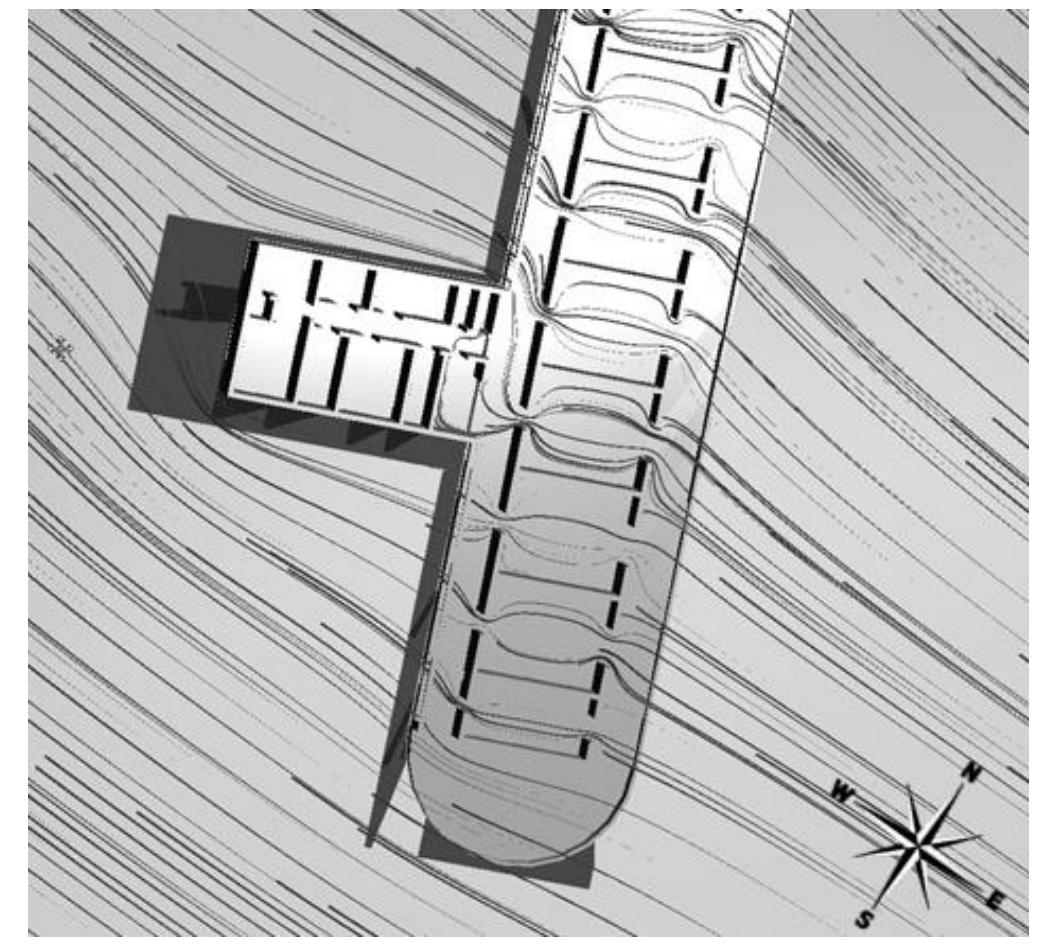

Figura 8 - Fluxo do vento predominante no verão, no interior das enfermarias do Hospital Santa Terezinha -

Fonte: Autores, baseado em AutoDesk Flow Design (2019) 
Como observado nas simulações, a configuração do Sanatório proporciona uma boa distribuição de fluxo de vento interno, que realiza uma varredura eficiente nos compartimentos de alojamento dos pacientes.

\section{CONCLUSÕES}

Ao se avaliar a edificação estudada, fica claro que as decisões projetuais tomadas pelos arquitetos modernistas levaram em consideração as variações climáticas ao longo do ano na cidade de Salvador, procurando auxiliar no processo de restabelecimento dos pacientes.

A partir desse conhecimento, os arquitetos propuseram uma edificação com o predomínio do comprimento longitudinal, de modo a proporcionar, a todos os compartimentos de permanência de doentes, acesso direto a uma grande varanda, para a aplicação da helioterapia. Esta solução também facilita a ventilação cruzada, proporcionando maior conforto e diminuição da quantidade de partículas sólidas, vapor d'água e micro-organismos no ar. $\bigcirc$ conforto ambiental é obtido a partir da função original do hospital, que utiliza a luz e ventilação natural como elementos de auxílio à cura.

Conclui-se que a edificação teve orientação e forma cuidadosamente estudadas, de modo a proporcionar as melhores condições ambientais para o tratamento da tuberculose pulmonar na época, constituindo-se em um exemplo claro da utilização da arquitetura como participante do processo terapêutico em relação à doença. Como sugestão para pesquisas posteriores, seria interessante a constatação do índice de letalidade da tuberculose entre internados no sanatório, no período anterior ao uso dos antibióticos.

\section{AGRADECIMENTOS}

Ao CNPq, pelo apoio recebido.

\section{REFERÊNCIAS}

ASSOCIAÇÃO BRASILEIRA DE NORMAS TÉCNICAS (ABNT). NBR 15220: 2005. Desempenho térmico de edificações, parte 3: Zoneamento bioclimático brasileiro e diretrizes construtivas para habitações unifamiliares de interesse social. Rio de Janeiro: 2005.

ANALYSIS SOL-AR. LAB-EEE. Disponível em:

<http://www.labeee.ufsc.br/downloads/softwares/analysis-sol-ar>. Acesso em: 1 jun. 2019.

ANDERSON, J. Computational Fluid Dynamics. Nova York: MCGraw-Hill, 1995.

ANDRADE JÚNIOR, N. V. Arquitetura Moderna e as Instituições de Saúde na Bahia nas décadas de 1930 a 1950. In: SOUZA, C. M. C.; BARRETO, M. R. N. (Orgs.). História da saúde na Bahia: instituições e patrimônio arquitetônico (1808-1958). Barveri, SP: Manole, 2011. p. 101-145.

AUTODESK FLOW DESIGN. Autodesk. Disponível em: <https://www.autodesk.com/education/free-software/flow-design>. Acesso em: 1 jun. 2019.

BIERRENBACH, A. C. S. Os traços das arquiteturas modernas de saúde em Salvador. Cadernos de Arquitetura e Urbanismo, v.24, n.34, 2017. 
CHU, C.R.; CHEN, R.H.; CHEN, J.W. A laboratory experiment of shear-induced natural ventilation. Energy and Buildings. v. 43, n. 10, p.2631-2637, oct. 2011.

MACHADO, A. S. A história da pneumologia na bahia: tributo ao professor César Augusto de Araújo. Gazeta Médica Bahia, v. 77, n. 2, p.195-209, jul./dez. 2007. Disponível em:

<http://www.gmbahia.ufba.br/adm/arquivos/artigol4_20072[1].pdf>. Acesso em: 1 jun. 2019.

\section{MATOS, L.; OTEMBRA, G. Cadastro Hospital Especializado Octávio Mangabeira.} 2018. Plantas em DWG.

MORAIS, J. M. S. C.; LABAKI, L. C. CFD como ferramenta para simular ventilação natural interna por ação dos ventos: estudos de caso em tipologias verticais do "Programa Minha Casa, Minha Vida". Ambiente Construído, Porto Alegre, v. 17, n. 1, p. 223-244, Mar. 2017. Disponível em: $<$ http://www.scielo.br/scielo.php?script=sci_arttext\&pid=S1678$86212017000100223 \&$ lng=en\&nrm=iso>. Acesso em: 1 jun. 2019.

QUECEDO, C. R. Arquitectura Terapéutica: El Sanatório Antituberculoso Pulmonar. 459 p. Tese (Doutorado em Arquitectura) - Departamento Teoría de La Arquitectura y Proyetos Arquitectónicos, Universidade de Valladolid, 2012.

ROCHA, D. F. Arquitetura Sanatorial: do projeto à reabilitação. 177 p. 2015. Dissertação (Mestrado em Engenharia) - Universidade de Beira, Curso de Engenharia, Covilhã, Portugal, 2015.

SANTOS, M. E. P. Entre os muros da exclusão: Hospital São Cristóvão dos Lázaros. 2005. Dissertação (Mestrado em Arquitetura) - Faculdade de Arquitetura, Universidade Federal da Bahia, Salvador, 2005.

SKETCHUP. SketchUp. Disponível em: <www.sketchup.com>. Acesso em: 1 jun. 2019.

SOUZA, C. M. C.; BARRETO, M. R. N. (Orgs.). História da saúde na Bahia:

instituições e patrimônio arquitetônico (1808-1958). Barveri, SP: Manole, 2011. Anexo V15.

WINDFINDER. Previsões de vento. Disponível em: <https://pt.windfinder.com>. Acesso em: 1 jun. 2019. 